\title{
Perspectives on Complexity, Its Definition and Applications in the Field
}

\author{
MATTHIJS KOOPMANS \\ Mercy College (USA)
}

There is considerable variation in the dynamical literature in how the term 'complexity' is used. While there have been several attempts to describe from an educational perspective what complexity encompasses, the term is frequently used without an explicit definition. To forge a shared understanding of what complexity means, the purpose of this article is to define the term for the field in a way that acknowledges the variety of use that is encountered in the education. Four perspectives on complexity are offered: 1) Information theory, 2) Cybernetics and general systems theory, 3) The use of complexity to describe scenarios of transformation and 4) Complexity as a metatheory. The implications of each of these four conceptualizations for educational research and practice are discussed.

The potential value of complex dynamical systems (CDS) and nonlinear dynamical systems (NDS) approaches has not been widely appreciated in education until relatively recently, when there was a spurt of significant scholarship in this area, including important theoretical contributions by Davis and Sumara (2006), Doll (2008), Osberg and Biesta (2010), as well as significant empirical work (Koopmans \& Stamovlasis, 2006). The potential contribution of CDS to the field of education lies in the fact that it provides an alternative paradigm, offers a different focus, different terminology, inspires us to ask different questions, and may suggest answers that have eluded normal science in education for a long time. Some of the important issues in the field seem to be particularly suitable for a dynamical systems approach, such as the efficacy of the interaction between teachers and students, the dynamical underpinnings of school reform, discontinuous learning trajectories and the causal connections between the behavior of educational organizations and that of the individuals residing within those organizations (and vice versa). The application of CDS to education also comes with some particular challenges that we are now only beginning to appreciate, such as the need to develop 
adequate measurement models as well as a coherent program of research. However, for such research to yield a workable body of knowledge about the dynamical process of education, there needs to be a clear shared understanding of what complexity means. The present article aims to address this issue.

There has been a fair amount of reflection over the years within the CDS literature about the diversity that exists among scholars as well as others in their understanding of the basic constructs of the discipline (Abraham, 1995; Davis \& Sumara, 2006; Goldstein, 1995; Osberg \& Biesta, 2010). Granted that the profusion of meanings and interpretation of the constructs can stimulate creative fermentation, it can also result in a great deal of confusion as people use key constructs differently (Goldstein, 1995). In part, this confusion has to do with the fact that terms like 'chaos' and 'complexity' have their popular use in addition to being theoretical constructs with very specific definition. However, there is also differential use of those terms within the CDS community, including interpretations that go beyond any strictly mathematical definitions. Abrahams (1995) refers to this taking of liberties as 'linguistic stretching.' Regardless of one's position with regards to this issue, few would disagree that many of the key constructs within the CDS conceptual tool kit are in need of clear definitions. This article focuses on the term complexity, one of the key constructs in the dynamical field.

Complexity is not a uniformly defined construct in CDS. Some call systems complex to refer to the wide variety of ways that open systems can interact with their environment (e.g., Kauffman, 1993), others do so because the internal structure of a system of interest is hierarchical, multifaceted, and governed by circular cause and effect loops (McKelvey, 1999), can display both high levels of order and high levels of disorder (Goldspink, 2007), is a state of being at the edge of chaos (Larsson \& Dahlin, 2012; Waldrop, 1992), yet others talk about complexity in terms of the predictability of a system's behavior (e.g, Biesta, 2010; Trombly, 2014) or in terms of the dependence of organizational forms on the environmental pressures to which the systems are responding (Kauffman, 1993; Levinthal, 1997; Nicolis \& Prigogine, 1989). Systems may be called complex because they are 'hard to handle' or 'difficult to understand' (van Geert \& Steenbeek, 2014), either on account of some combination of the characteristics listed above or for other reasons. There also reference to the complexity of organizations outside of the confinements of the CDS literature, without there being a clear demarcation of the term 'complexity' as a dynamical construct (e.g., Perrow, 2014; Finerty, 2012).

Over the past decade, the term complexity has readily made inroads into the educational literature, which now includes references to complexity in the discussion of educational change at the school and district level (Lemke \& Sabelli, 2008; Trombly, 2014), learning systems (Davis \& Sumara, 2006), curriculum (Doll, Jr., 2008; Hussain, Conner, \& Mayo, 2014; Smitherman, 2005), pedagogy (Phelps, 2005), research methodology (Hetherington, 2013; Koopmans, 2014), epistemology (Alhadeff-Jones, 2008; Gilstrap, 2011; Le Moigne, 2013), classroom dynamics (Semetsky, 2005), English as a second language writing (Nelson, 2004), spirituality (Low, 2008), creativity (Trueit, 2005) and ethics (Bai \& Banack, 2006).

The purpose of this article is to explore the productiveness of this variability of definition and usage for the field. This article is not the first to attempt to define the term complexity and discuss its potential relevance to education. Alhadeff-Jones's (2008) and Davis and Sumara's (2006) reviews preceded this one. Both are concerned with the definition and use of the term, as 
is this article. Alhadeff-Jones focuses on the historical evolution of the construct and its use, while Davis and Sumara are primarily concerned with a description of its various aspects and their relevance to the field of education. Where the current article differs from the other two is in its deliberate exploration of the productiveness of the differences in usage, including an assessment of the continued relevance of the older conceptualizations such as those from information theory and cybernetics, as well as more recent ones, such as emergence and selforganized criticality. This article proposes a way of viewing the complexity phenomenon based on some of the dynamical literature and seeks to illustrate how this variety of viewpoints enriches our vocabulary when talking about transformative scenarios in education. It should be seen as part of an ongoing conversation about how to apply complexity productively in education, and is not meant to preclude other definitions.

\section{WHAT IS COMPLEXITY?}

Merriam-Webster (1990) defines complexity as 'the quality or state of being complex,' and defines the term complex, in turn, as being a whole made up of many interrelated parts. Most definitions of the term that can be found in the dynamical literature continue to subscribe to these features, but with additions and qualifications that distinguish the term from common usage. Alhadeff-Jones (2008) provides a useful and very readable account of the variety of ways in which the term has been defined as well as its etymological roots. More importantly, he also provides a chronological discussion of how sub-disciplines within the dynamical field have used the term differently, and includes such perspectives as information theory, cellular automata, cybernetics, systems science, self-organization, chaos and catastrophe theories, and complex adaptive systems. The present discussion expands on some aspects this historical account by identifying four different readings of the term complexity. Firstly, there is the use of complexity as a characterization of cognitive and information structures, as can be found, for instance, in Shannon's (1948) information theory and Piaget's (1967) schemata. The second reading, which originates in cybernetics (Ashby, 1957, 2004/1962; Wiener, 1961) and general systems theory (von Berthalanffy, 1967, 1969), views complexity in terms of the conditionality and irreducibility of interactive behavior in systems. Third, more recent theories have focused on complexity as a family of dynamical scenarios to describe the transitions between states with meta- and instability and unpredictability triggering systemic transformation (Davis \& Sumara, 2006; Nicolis \& Prigogine, 1989). Lastly, there is the perspective of complexity as a metatheory predicating a paradigm shift, a notion that has been forwarded by Fleener and Merritt (2007), Jörg, (2011), Jörg, Davis and Nickmans (2007) and Morin (2008) among others. Below is an elaboration on each of these four perspectives. It is anticipated that this discussion will help the reader appreciate the different ways that the idea of complexity can be qualified in our scholarly discourse and illustrate the many different ways we can use it to build theories about educational processes and their impact on learning and achievement.

\section{Cognitive and Information Structures}

In his classical paper, A mathematical theory of communication, Shannon (1948) was concerned with the engineering aspects of a reliable transmission of information in communication 
systems (telegraph, telephone, radio, television), and the non-randomness in the signal sequences that permits effective decoding of the information. In its simplest mathematical form, one may think of such sequences as strings of possible outcomes. One scenario is that each outcome in a given sequence of possibilities has equal probability values attached (e.g., $0.2,0.2$, $0.2,0.2,0.2)$. In this case, the string carries little information about which of the five outcome might occur next, thereby provoking a random choice and maximum uncertainty. If, on the other hand, a string contains unequal probability values with some outcomes preferred to others (e.g., 0.4, 0.1, 0.2, 0.2, 0.1), uncertainty in decoding the information is reduced. The first pick is more likely to be the right one than the other four because of the higher probability value attached to it. A further reduction in uncertainty can be accomplished if the probability of certain outcomes is made conditional upon previous outcomes, i.e., when knowledge about previous occurrences can be used to improve the prediction of future outcomes (i.e., conditional probabilities). The uncertainty associated with the predictability of such outcomes is called entropy, i.e., the degree of irresolution contained by a given set of information elements.

In his paper, Shannon uses the term 'complicated' twice and the term 'complexity' once. In all three instances, he refers to an increase in complexity that results from making probabilities conditional upon previous occurrences, and its effect of reducing uncertainty, or entropy. In this formulation, then, entropy is related to complexity as follows: if probabilities of subsequent occurrences are conditional upon previous ones, there is less entropy because of our ability to use previous information to make predictions, but there is greater complexity in the sense that the probability space is organized in terms of previous outcome distributions. There is an inverse relationship in this scenario, then, between complexity and randomness: introducing complexity may or may not reduce randomness in the probability space, but will never increase it (Shannon, 1948).

As an example, imagine the animal kingdom as the accumulation of an undifferentiated mass of characteristics (wings, eggs, gills, feet, insects, fight and flight behaviors, vertebrae, cats and geese) in which any form of recognition on our part is a trial and error process. Next, consider how the active construction of groupings, such as those corresponding to species, genera and classes facilitates the recognition and recollection of characteristics and behaviors. Animals typically breed within species, not across; mammals bear their young, reptiles and birds lay eggs, fish have gills, etc. The introduction of complexity through the Linnaean classification system reduces uncertainty in the recognition of animal types and in the prediction and understanding of their behavior. It also helps understand the evolutionary processes, which is to say, the dynamical processes which underlie those distinctions in the first place.

Piaget (1971) draws an interesting parallel between the evolution of 'organized creatures' (p. 71) and the gradual formation of intelligence in the individual organism. While those two developmental processes are very different in many respects, they have in common a process of differentiation. Evolution involves a growing differentiation of species while intellectual development involves individuals building increasingly differentiated frames of reference as a result of accommodation and reflective abstraction. Accommodation is a restructuring of the individual's frame of reference to address contradictions between existing frames, or schemas, and new input from the environment. As a consequence, 'finer and finer distinctions are made 
between and within schemas or concepts' (Ginsburg \& Opper, 1988, p. 224), and a progressively more complex system of operational capabilities is established (Piaget, 1970). Reflective abstraction is the process through which the individual revisits its mental structures as it considers its own actions in relation to given objects, or evaluates the effectiveness of its mental structures dealing with new environmental input. In both instances, reflective abstraction involves accommodation and results in a broader understanding as well as a better ability to assimilate new input on the basis of existing mental structures.

Complexity Reduction

Biesta (2010) offers some essential insights into the relationship between complexity and learning. He rightly notes that learning, and by extension, formal education, permits us to reduce an infinite number of possible interpretations of our surroundings into more parsimonious conceptual frameworks to enhance our understanding of the world, make the future more predictable and permits us to better reflect on the limitations of our understanding (Biesta, 2010). Reducing the number of available options for action for the elements within a system is called complexity reduction. An example of complexity reduction is the establishment of set organizational and/or classroom routines. These reduce complexity in the sense that they restrict the behavioral options available to students. Other examples are the distinction of specific behavioral changes as learning as distinct from other behavioral changes, and the establishment of a grade-level-based classroom structure within school buildings instead of random placement of students. Complexity reduction as defined here is concerned with the multi-faceted character of the systems in question, not the irreducibility to the behavior of actors and subsystems. Reducing complexity to simplicity in this latter sense involves the dissolution of an organization in the sense defined by Ashby (2004/1962) into a set of loose individual components whose behaviors are no longer contingent upon one another.

The compatibility of Biesta's terminology with the formulation outlined above warrants closer scrutiny, however. Biesta introduces the term complexity reduction to describe how we enhance our grip on our surroundings: 'formal education can be seen as an example of complexity reduction in human learning, as it instills those schema we need to understand and predict reality.' (p. 9) He also notes that 'complexity helps understand the complex character of the physical social world. How is the reduction of complexity achieved?' (p. 7). The wording of this latter observation raises more fundamental questions, though. If complexity helps better understand the world around us, why would we want to reduce it? How can formal education be productive if it exemplifies such a reduction? The notion of complexity forwarded here seems to stand in diametric opposition to Shannon's proposition of an inverse relationship between complexity and randomness. Here, they seem to be positively correlated in the sense that reducing complexity and reducing randomness somehow go hand in hand. The incorporation of the entropy construct into Biesta's conceptual framework might help resolve this contradiction. This adjustment would permit us to associate randomness with entropy rather than with complexity, and argue that complexity reduction is shorthand for the reduction of entropy through increased complexity. This rephrasing would be compatible not only with Shannon's insights but also with Piaget's notion of learning through the use of increasingly differentiated schemas. 
In virtual and cognitive task environments, complexity can of course be readily manipulated, both by reducing it and by enhancing it (Tijus et al., 2007), and the manipulation of such complexity is, for teachers, an important tool for managing task difficulty. The reduction of complexity in that sense can be an important scaffolding tool (Jörg, 2011). Ultimately, however, learning in the Piagetian sense, is usually presumed to involve a progression toward more complex cognitive structures, rather than simpler ones, resulting in better adaptation (Piaget, 1967).

\section{Conditionality and Irreducibility in Interaction}

The notion of complexity as a property of systems, implicit in the formulation above, requires further elaboration. Classification systems and schemata are but two of many examples of systems whose complexity can be investigated. A more general view of systems and their properties has been forwarded by von Berthalanffy $(1967,1969)$, who posits that systems of all kinds share certain essential features, and that studying those features would be a productive scientific endeavor, hence the name general systems theory (GST, von Berthalanffy, 1969). GST views the behavior of a system in terms of that of its constituent components and the interrelationships between those components. These components are often called subsystems and they may consist of either individuals or groups of individuals constituting subgroups of the larger system. The unit of interest and analysis in GST is therefore the system plus its subsystems and it allows for the flexibility to alternate between the individual and the (sub) systemic level of description. GST also presumes that individuals and subsystems cannot be isolated from the larger systems that they are part of, and conversely, that systems cannot be understood without analyzing the behavior of its constituent components. GST involves not only the identification of the components of a given system, but also the description of the relationship between those components. Those interactions are typically understood in terms of the exchange of matter, energy or information (von Berthalanffy, 1969). Where the dynamical view of complexity differs from the more structural view outlined above is that complexity is seen as a process instead of a state. The distinction of complexity as a state and complexity as a process is crucial to a full understanding of the application of CDS to education where the description of the dynamical aspects of such things as the interaction between teachers and learners interaction, between parents and teachers, parents and students, as well as the interplay between school buildings and school district level policy, is what distinguishes the CDS perspective from more conventional scientific approaches.

The cybernetic literature further qualifies the conventional understanding of complexity by defining systemic organizations in terms of the conditionality of the behavior of individual elements on that of other elements (Ashby, 2004/1962). The implication of this notion is that something is an organization once the behaviors of its members and subsystems are interrelated, and that the manifestation of such interrelationships in the interaction between individuals defines them as being part of an organization. This distinction between multiple levels of description, one for individuals and one for the organization of which they are part is consistent with the insights of GST and the notion of complexity as a whole with interrelated parts. Where the cybernetic perspective on complexity differs from a static one is in its introduction of the notion of irreducibility, the idea that behaviors at higher systemic levels of 
description may not be readily reducible to those of individuals if they are the constituents described by that higher systemic level. It follows from this insight that organizations are complex by definition (Koopmans, 2016). From the cybernetic perspective, then, the interrelationship between the behavior of individuals and the systems of which they are part, and the notion of irreducibility, are defining characteristics of complexity as a process. Individual and their organizations interact in an ongoing interrelationship where the behavior of individuals is delineated or facilitated by that of its system(s) while the behavior of the system is an expression of how its individual constituents within it communicate to assert it. This mutual interdependency between the system and its components, and the irreducibility of the behavior of the former to the latter can be viewed as a defining characteristic of complexity as a process, distinguishing it from the notion of complexity merely as a multifaceted phenomenon or behavioral manifestation. The idea of systemic hierarchy and irreducibility as a manifestation of complexity sets it apart from complex networks, i.e., the occurrence of fractality in the node structure of social networks, which may illustrate an aspect of complexity, but does not necessarily require the assumption of irreducibility (Davis \& Sumara, 2006).

The implication of the complexity view forwarded here, is that it is a process that plays itself out over time, rather than merely being a state of intricacy. In other words, we understand its behavior in terms of its previous manifestation, rather than as a snapshot that is frozen in time. Understanding behavior in terms of its previous manifestation, and the prediction of future behavior in terms of current and past behavior refers to the endogenous process in the system, and its analysis is part and parcel of the CDS perspective. The exogenous process, on the other hand, refers to the influence of external factors and variables on the behavior of a system. CDS argues that both need to be considered in conjunction in order to understand systemic stability and change. The methodological predisposition that follows from these insights is that many repeated observations of the behavior of a system are needed to understand its causal underpinnings (Koopmans, 2015).

The hierarchical features of complexity are exemplified in the idea that classrooms are entities that have characteristics in their own right, such as climate and conduciveness to learning, that are not reducible to those of the individual teachers and learners within them, although both have a decided influence on the variables describing the classroom system. The implication of the hierarchical viewpoint outlined above is that educational change can be described in terms of the interaction between individual agents such as teachers and students on the one hand, and the larger systemic constellations of which they are par (Trombly, 2014). The higher level characteristics (e.g., classroom climate) arguably influence the possibilities and constraints on individual student learning, while at the same time, the extent to which learning and productive interactions take place have a decisive influence on this climate and how it would be perceived, by the participants themselves as well as by others. This circular relationship between the behavior of individual agents and the systemic constellations of which they are part illustrates the notion of recursive causality (Koopmans, 2014), which is an important and under-researched aspect of how we seek to describe educational change.

The notion of recursive causal loops in complex systems also gives us a better perspective on the extent to which educational change can be triggered through bottom-up versus topdown processes in complex systems (Koopmans, 2014). In the school reform context, for 
instance, there is little doubt that the interplay and communication between classrooms and the school building is relevant when it comes to school improvement, but the educational literature does not present a consistent point of view as to the prevailing, or most desirable, direction of such changes: Are they primarily a matter of classroom compliance with certain mandates, curricular and otherwise (top-down), or should the primary engine of reform be classrooms exchanging information about effective practices that then get codified at the institutional level (bottom-up)? At the level of classroom processes, the complexity perspective similarly begs the same question about how change is accomplished through interaction across systemic levels. It encourages making a distinction between classroom learning through collaborative exercises (bottom-up) and teacher-directed pedagogy (top-down). Recursive causality, in other words, goes in both directions while cutting across the hierarchical levels that define the complexity of the system. In this way, the recursive relationship between cause and effect arguably lies at the core of the learning process (St. Julien, 2005). In this scenario, behavior in the classroom is not reducible to that of the individual students residing within it, and cognitive schemas cannot be reduced to their constituent information elements, or to individual transactions with the environment.

\section{Performing Transitions between States}

In much of the discussion from the two above mentioned vantage points, complexity is seen as a feature that systems inherently possess or lack, either as a structural or as a process feature. In their excellent overview titled Exploring Complexity, Nicolis and Prigogine (1989) prefer instead to speak of complexity as a set of possible transformative behaviors that different types and classes of systems may share with one another, and it typically includes those behaviors where the scope and nature of the changes cannot be readily deduced from the initial conditions residing in the system. Based on examples from various disciplines, Nicolis and Prigogine seek to find the commonalities between systems, and while their emphasis is on chemistry, physics and biology, their ability to demonstrate of the applicability of transformative models that are specific in the abstract across different fields of knowledge is what makes their search of particular interest. The extension of such change models to education can be readily appreciated by the fact many have already been investigated empirically, such as hysteresis (Stamovlasis, 2006; Stamovlasis \& Tsaparlis, 2012), non-periodic attractors (Koopmans, 2015), emergence (Hussain et al. 2014) and self-organization and fractality (Fromberg, 2010, 2016). A discussion of complexity in terms of its transformative capabilities can also be found in Davis and Sumara (2006), who distinguish the construct defined in this way from complicity, i.e., systemic novelty due to repeated interactions, and simplexity, the emergence of simple linear features in complex systems (Stewart, 2007).

The notion of complexity as a characteristic inherent to the system presupposes that some systems are complex (e.g., living organisms), whereas others are not (e.g., the swing of a pendulum). Nicolis and Prigogine (1989) challenge the necessity of that assumption with an illustrative metaphor. A cubic centimeter of water contains interactions between huge numbers of molecules, but the vastness of the interaction pattern by itself would not be enough to call it complex because there does not appear to be any coordinated activity or other dynamics. If, on the other hand, this cubic centimeter of water is exposed to the conditions of a winter storm, the 
result may be intricately patterned snowflakes. The complexity, in this example, has to do with the behavioral response of a system to an environmental contingency, rather than with a feature that operates irrespective of any external input to the system. Whether the system is complex or not, in other words, depends on circumstances such as these.

The distinction between stability and turbulence has been a central feature of the dynamical systems literature for a long time. In his force field theory, Lewin $(1947,1951)$ writes about systemic change in terms the turbulence that accompanies the transformation in a system from one state to another. While the perturbation is an important part of the transformative process, the system ultimately settles down into a new state once transformation has been accomplished. One of the essential features of complex behavior seen this way is 'the ability to perform transitions between different states' (Prigogine \& Stengers, 1989, p. 36). Seen as such, complexity could refer to a rich assortment of transformative scenarios (Koopmans, 2009), and over time, increasingly sophisticated scenarios have been presented in the literature. Examples of such 'complex' transformative behaviors are the hidden potentialities in equilibrium situations, small perturbations producing large effects, and the potentialities that have multiple solutions such as catastrophic changes through which systems go from one state to another. The complexity in these situations lies in the nonlinearity of the relationships between the initial conditions and the outcomes (Nicolis \& Prigogine, 1989) instead of a straightforward linear relationship between variables, which would exemplify 'simplicity.'

In a state of equilibrium the behavior of the system is relatively predictable and variability tends to be low. Turbulence in those systems, on the other hand, marks a process of transformation with unpredictability and high variability in behavior until the system settles down in a new equilibrium state, and in that state, the system tends to dampen or reduce fluctuations that stray of its equilibrium settings (Goldstein, 1988). Inspired by developments such as synergistics (Haken, 1984, 1988) and chaos theory (Prigogine \& Stengers, 1984) this set of assumptions about stability and transformation gave way to a more liberal view about stability and transformation that acknowledges that systems may be in a state of ongoing perturbation, and that, in fact, less stability may lead to greater adaptiveness of systems to changing environmental circumstances, as well as opportunities for novel adaptive solutions (Goldstein, 1988, 1990). Far from equilibrium behavior illustrates complexity by its nonlinearity, the possibility that small events may have large repercussions; that multiple adaptive solutions are available at some given input values and that radical transformation may occur as a result of small behavioral fluctuations, given that a system has a disposition to be responsive to such fluctuations.

There is no need to point out to educational practitioners (teachers, parents) that education systems are complex in the sense that outcomes not always easy to predict on the basis of input conditions. Consider the impact of one teacher remark on each of a classroom full of students, or the shift that may occur in the interaction between students and teachers when students' frame of reference about a given curriculum segment once it gets elevated to a higher level of understanding. In school reform situations, similarly, small changes at the local level, such as the development of an effective instructional module that is shared with neighboring classrooms and may reverberate throughout the school building. These kinds of transformations all illustrate complexity as performing transitions in educational settings. The 
abstract definitions of transformation can help inform the discussion about learning in the classroom, or the merits of bottom up and top down processes when it comes to school reform, such as, for example, the aforementioned dissemination of local practices (bottom up), or shocking school systems into transformative turbulence by, for instance, introducing marketbased competition into the system (Koopmans, 2016).

An important aspect of complexity as the production of transformations is the notion of emergence, the evolution of incidental fluctuations into radically novel patterns of behavior (Goldstein, 1999, 2014). While emergence seems to evolve out of random patterns of behavior, the theory holds that some kind of proclivity toward transformation already needs to be present in the system to enable it to materialize at some critical point. For emergence to occur, systems need to already have a transcendent quality. This notion of appreciating the state of a system in terms of its 'change potential' is of interest because it shifts the attention of researchers and practitioners from the resultants of change efforts to the assessment of elements and characteristics of systems in their baseline state that may show a proclivity toward transformation. Finding such potential is important in classrooms, for example, to describe whether the physical and social climate is conducive to learning, or in schools more in general to estimate the potential effectiveness of new educational interventions.

The Edge of Chaos and the Phenomenological Coefficient

Waldrop (1992) defines complexity specifically as an intermediate state between chaos and order, the extreme manifestations of disequilibrium and equilibrium, respectively. He defines complexity in terms of its proximity to the former state, and notes the following:

Right in between those two extremes .... at a kind of abstract phase transition called "the edge of chaos," you also find complexity, a class of behaviors in which the components of the system never quite lock into place, yet never quite dissolve into turbulence, either (Waldrop, 1992, p. 293).

Complexity here refers to a critical state of the system, which is not quite stable but in which a qualitative transformation may be imminent (meta-stability). The archetypical example of this understanding of complexity is the sand pile over which additional grains of sand are poured up to the point that the sand on the pile shifts to reduce the friction between grains (Bak, 1996; Jensen, 1998; Koopmans, 2014). This process is also often referred to as self-organized criticality, the potential for imminent transformation in systems due to the accumulation of certain input conditions.

Interestingly, Nicolis and Prigogine (1989) define a similar boundary condition toward the other end of the spectrum between chaos and order called the phenomenological coefficient, a system parameter characterizing nearness to equilibrium, i.e., closeness to a transition in which nonlinear equations and complexity cease to be effective predictors of the systems' behavior. In the realm of research, an example of such would be the continued attempts to fit nonlinear analytical models to straightforward linear situations. This nearness to equilibrium is also an important aspect, for example, of the question of sustainability of educational innovations and new interventions. Many school reformers argue that the size of school systems (they are often very large) and the scale of transformation that is attempted (very ambitious), create a great potential of the system to fall back into its original settings, as the innovations lose momentum 
in the long run, funders move on, long-standing conflicts in the system remain unresolved, budgets are not adjusted to support the changes, and many classroom and school building practices (effective as well as ineffective ones) have not been abandoned to accommodate the ones that come with the new initiative (Hess, 1999; Koopmans, 2016).

\section{A Metatheory Predicating a Paradigm Shift}

The sections above discuss complexity as an object of study. Phenomena may or may not exemplify it, and our methodologies may or may not be capable of detecting it. Complexity theory is also often seen as a metatheory representing a paradigm shift in the Kuhnian sense (Kuhn, 1970), which is to say that it is a conceptual model that redefines the way science is done, opens up a set of new questions and priorities for scrutiny, provides opportunities to address questions to which existing paradigms have failed to find satisfying answers and establishes a new sets of norms for descriptive and explanatory adequacy of its theories. In fact, many of the examples given above illustrate these new areas of interest. The term 'paradigm' can be defined as a constellation of values, beliefs and methodological assumptions (Fleener \& Merritt, 2007; Kuhn, 1970), and in that capacity, it sets priorities for theory development and empirical research. Paradigm shifts in the Kuhnian sense represent reformulation of the conceptual frameworks guiding our knowledge acquisition to accommodate the challenges to existing ones (Kuhn, 1970). For that reason, a theory or paradigm is an important object of study in its own right, as is the question how complexity theory would redirect the scientific dialogue in education.

Complexity theory has been presented as a paradigm shift that replaces traditional logicalpositivism with a new set of assumptions and methodological priorities for empirical research, a perspective that explicitly sets out to investigate discontinuities, ruptures and emergence instead of relying on commonalities and the central tendency in groups (Fleener \& Merritt, 2007). Morin characterizes this shift in terms of whether scientific theories seek to attain simplicity through the development of parsimonious explanations or complexity through the description of wholes in terms of their interrelated parts, and fully dichotomizes the scientific pantheon as aspiring either the former or the latter (Alhadeff-Jones, 2010; Morin, 2008), comparing the two approaches in terms of eleven basic principles (see Table 1). This table shows complexity and simplicity as two alternate paradigms to inform the scientific endeavor and they are formulated as a meta-theory that supersedes theoretical work and empirical data collection within specific areas of knowledge. The dichotomy is used here to characterize where the theoretical and empirical realm stand in relation to each other in each of these two broad orientations. As is often the case with such dichotomizations, they do not do full justice to the nuances typically involved in scholarship (nor do they fortify the argument against reductionism very well). However, they provide a useful heuristic to help appreciate how complexity is seen as being different as from the conventional scientific paradigms. The term 'simplicity is perhaps somewhat dismissive here. From the eleven principal distinctions listed in the table above, I propose to distill the following essential main ideas of how complexity theories are most typically understood as being different from conventional science. One is the emphasis of the temporal aspects of systemic behavior (with or without irreversibility) and the importance of its history (Principle 2). The second is the relationship as we would understand it 
Table 1. Principles of Simplicity and Complexity According to Morin (based on AlhadeffJones, 2010)

Simplicity
1. Principle of universality at the expense of
the local, singular or residual
2. $\quad$ Elimination of temporal irreversibility
3. $\quad$ Principle of reduction from understanding
4. $\quad$ Principle of reduction of organization to
rules of order

10. Principle of absolute reliability of establishing intrinsic truth of theories

11. Foundation of thought based on clear and distinct ideas and monological discourses

\author{
Complexity \\ Promoting interpretations starting from the \\ local and the singular \\ Recognizing irreversibility and include history \\ in description and explanation \\ Link knowledge about individuals to the \\ wholes they belong to \\ Organization and self-organization represent \\ problematics that cannot be ignored \\ Principle of complex causalities including \\ mutual causality and feedback loops \\ Interpreting phenomena through circular logic \\ linking order disorder, interaction and \\ organization
}

Principle of distinction instead of disjunction between object, subject and their environment Principle of relationship between observer/designer and object of study

Possibility of a scientific theory of self and autonomy, self-production and selforganization

Limits of logical demonstrations through formal complex systems

Cross-disciplinary thinking; question links between constructs

between the system's behavior and that of the constituent elements, to which the system's behavior cannot be reduced (i.e., the whole is greater than the sum of its parts, Principles 3 and 4). This is complexity in the narrow sense of the word, as defined in cybernetics.

The third main idea in Morin's juxtaposition is the search for causality as a recursive rather than a linear process (Principles 5 and 6). This idea is also related to complexity in a the narrow sense of the word, in that understanding systems behavior requires appreciation of how the behavior of individual members of system causes the behavior of the larger constellation, and, conversely, how the behavior of the system as a whole predisposes individual members within the system to behave a certain way toward one another. Emergence and novelty, two fundamental constructs for describing systemic change (Goldstein, 1999, 2014) rely critically on the description of the interaction between multiple and mutually inclusive levels of the system. Understanding these relationships is seen as a fundamental aspect of the study of cause and effect relationships that can be accommodated within complexity theory. The fourth main idea is that a complexity perspective views the behavior of individuals in their systemic context instead of isolating the individual from it, as is traditionally done when random samples of individuals are taken whose behavior gets observed without regard of the dynamics of the 
individual's systemic affiliations (Principles 3, 4 and 5). From this standpoint, it may be seen as more productive to examine learning behavior, for example, in the context of classroom interaction among learners, rather than a sampling of learning outcomes that are analyzed irrespective of the context in which they were generated.

The dichotomy enumerated above conflates two paradigmatic distinctions widely seen as very important to the field of education that should be kept apart here. One is the distinction between logical positivism versus more qualitatively oriented approaches such as phenomenology, idiographic approaches, ethnography and hermeneutics, this distinction is prominent in Principles 1,8 and 9. The other is between normal science and complexity, as expressed by Principles 3, 4, 5, 6 and 7. While inductive reasoning, as stated in Principle 1 has been productively used in work on complexity (e.g., Laidlaw, Makovichuck, \& Wong, 2013), it is not necessarily a defining characteristic of the perspective, which also accommodates the productive use of deductive methods to confirm hypotheses about complexity (e.g., Stamovlasis, 2014). Likewise, the complexity angle does not require the use of qualitative research approaches. Although those methods are conducive to uncovering the dynamics of stability and change in behavior in real-time observation, sophisticated statistical methods are also utilized as well to study those processes on a case by case basis (see e.g., Guastello \& Gregson, 2011; Koopmans \& Stamovlasis, 2016). Furthermore, contrary to the epistemological position outlined in many qualitative textbooks (e.g., Bogdan \& Biklen, 1982; Lincoln \& Guba, 1985) arguing for an open-ended research agenda that minimizes theoretical preconceptions, the complexity perspective puts forward very distinct views about the processes that would be of interest to the researcher, such as those described earlier in this article.

Morin's principles 7, 10 and 11 touch upon broader ontological and epistemological positions that are not often part of how complexity is discussed, but they deserve closer scrutiny in future work. The question of subjectivity as an important aspect of social systems is also discussed by Holland (2002), Koopmans (2016) and McKelvey (2011), who acknowledge that while some basic features of the interactive behavior may discernible through simplicity as defined above (e.g., systems are comprised of interactive subsystems), other aspects such as emergence, self-organization and complexity require that we view social systems as a the product of shared meanings and interpretations of the social structures, on account of which interaction takes place within the system. The implication of the epistemological positions articulated here is that the relationship between knowers and their subjects is defined in terms of a systemic process, whereas the search for simplicity presupposes a reality out there in which the subject of knowledge resides outside of the self-referential process of the system (Le Moigne, 2013). Irrespective of how far one takes the idea of the subjectivity of our knowledge about systems, it is often argued that the perspective and history of the researcher in relation to the object of interest needs to be incorporated as a variable in the design and justification of the study, an idea that is also key to many ethnographic and phenomenological studies (e.g., Bogdan \& Biklen, 1982), and is, of course, a useful edict for any scientific endeavor.

Maturana (1970) takes this argument one step further by arguing that systems produce themselves through interactive behavior and the descriptions they provide of themselves are part of this interactive process, rather than representing an objective reality that resides outside of this process. Likewise, systems describing other systems form a new system that includes the 
process of description. Since systems are fully self-referential, the knowledge that they produce about themselves is therefore inherently subjective. This concept is also referred to in the literature as generative complexity (Jörg, 2011; Jörg, Davis, \& Nickman, 2007), or autopoiesis (Maturana \& Varela, 1973). The basic notion is that as complex systems adapt to their environments, they regenerate themselves on an ongoing basis as part of that process. Urry (2003), parenthetically, argues against the application of lens of autopoiesis to human ecologies such as education, because it subordinates the functionality of such systems to the autopoietic process, which is to say that things like poverty, inequality, terrorism and global warming could be seen as necessary functional components of the self-making process. The implications of the autopoiesis postulate and its challenges for the field requires fuller appreciation. As a feature of the homeostasis in biological systems (Maturana, 1970), its significance to the educational process is not self-evident, and therefore remains to be determined.

From a complexity standpoint, causality is a much more elusive construct than it would be in a reductionist framework, where we look for the realization in the real world of a linear relationship between variables as proposed in our models (Rosen, 1985). Morin's principles outlined above imply challenges on multiple fronts to this proposition: the relationship between the observer and the real world is not straightforward, causal relationships at higher systemic levels cannot be readily reduced to having those same causal relationships in all subsystems, there are questions about the generalization of cause and effect relationships based on group averages to the individuals that constitute the group, simplicity does not deal with the feedback relationships between cause and effect (Koopmans, 2014), and we cannot assume that whatever relationship, linear or otherwise may transpire between variables can be seen as fixed once and for all (Rosen, 1985). In experimental studies in education, for example, the complexity of our educational interventions, in 'experimental' and 'business as usual' conditions alike questions the assumption of one-to-one relationships between what we do and what the results are of our actions, and therefore requires extensive observation of the dynamics of the intervention process. Furthermore, generalizations from individuals to groups are not straightforward, given the processes through which individuals constitute the group, and the particularity of the causal process at the level of individual constituents of the system. The appreciation of the difference between complexity and simplicity in our understanding of causal structures in education has important implications for the field in terms of research, experimental and otherwise, as well as for the way research is utilized for school accountability purposes, such as the use of data to evaluate teachers, decide on school effectiveness, and inform organizational decision making.

\section{RECAP AND A FEW IMPLICATIONS}

Few practitioners would deny that education is a complex process. The dynamical literature provides array of complexity scenarios over and above the common usage of the term. The perspectives offered in this article are by no means meant an exhaustive treatment of how complexity might be used in education but summarize some of the basic understandings of the term in the dynamical literature and evaluate the implications of those for the field. The insights about complexity derived from information theory might help us think about the input material 
in instructional situations. The manipulation of input material through simplification to facilitate scaffolding the learning process in teacher student interactions is an example of what Biesta (2010) calls complexity reduction, the lessening of descriptive dimensions to the phenomenon of interest to facilitate understanding on the part of the learner. For instance, in mathematics instruction, one might explain multiplication and division before covering divisions with remainders, an essential feature that makes the computations more complex. Another implication of the information theory perspective on complexity has to do with the description of the schemata we use to understand the world around us. Piaget's developmental theory describes the growing complexity that those schemata attain in the course of the child's interactions with its environment, and the child's evaluation of the adequacy of existing schemata. The increases in complexity of schemata through accommodation is an expression of an adaptive process resulting in a dynamical equilibrium.

The notion of complexity as the irreducibility of the behavior of systems to the behavior of the constituent components, as described in the cybernetic and general systems literature, has wide ranging implications for educational research. In particular, it calls for the investigation of the interaction between systemic components at different levels of description (students, classrooms, school buildings, districts). To what extent does classroom level behavior affect the learning of individual students, and to what extent do the interactions between individual students within a classroom create an environment that is conducive to learning? This dynamical interplay between systemic levels also offers an alternative account of cause and effect in the educational endeavor, in that, rather than isolating behaviors from their context, the context of these behaviors becomes an integral aspect of our understanding of the cause processes that generate educational outcomes. This field of empirical investigation is almost completely open at this point. Requisite methodological discussions can be found in Koopmans (2014) and Salem (2013).

The interest in the dynamical literature in the dynamics of stability and transformation has given rise to a rich array of scenarios, including such processes as bifurcation, nucleation, emergence, second order change, hysteresis and much more. It goes beyond to purview of this article to discuss these in great detail (but see Davis \& Sumara, 2006, Koopmans, 2009 and Nicolis \& Prigogine, 1989). A good testing ground for possible application of these definitions is school reform. There is a widely held perception of inertia in the educational system in spite of the continuous supply of reform initiatives. Why is change so difficult? The CDS perspective can uniquely contribute to addressing this questions by defining the parameters of stability and change to find out what inhibits and facilitates it, and as well as evaluate the openness of given systems toward change before reform efforts and new interventions are undertaken

(Koopmans, 2014).

Understanding processes of change requires a focus on the particularity of the behavior of interest, as well as a detailed investigation of its progression over time. Koopmans and Stamovlasis (2016) provide extensive coverage of the methodological aspects of this issue. One of the broader implications of the complexity angle in education is that we need to investigate the details of the dynamical processes that result in transformation, the determinants of change and the baseline settings of the systems of interest. A wide range of statistical approaches is available to deal with these questions, such as catastrophe modeling (Stamovlasis, 2016a), 
fractional differencing (Koopmans, 2015, 2016b), state space grids (Pennings \& Mainhard, 2016) and orbital decomposition (Garner \& Russell, 2016; Stamovlasis, 2016b).

The focus on the specifics of dynamical processes also orients research to a field-based approach where systems behavior occurs in its natural environment. Phelps (2005), for example, rightly proposes that action research is a particularly suitable design for the study of complexity in education, as it allows for the interaction of the researcher with the system to be incorporated into the analysis and it is expressly concerned with the use of research findings to produce change in the field (Coglan \& Brannick, 2014). Action research designs create possibilities for the researcher to help translate the implications of the findings into actionable follow-up behavior, thus enabling researchers to help produce change for the better into the educational system. Where complexity differs from conventional ethnographic research is that it is armed with a detailed vocabulary of how change works in the abstract (Koopmans, 2009), and that vocabulary might help provide perspective on the discussion of educational transformation.

An example of an area where such vocabulary might help us is school reform. One approach to educational reform is to shock systems into transformation through the use of market-based economical models that create a market-based dynamic. The purported impact of this shock is that it forces systems out of their habitual response set, resulting in the kind of randomness that creates possibilities for finding new problem solving strategies and approaches. Regular public schools compete with public charter schools, improvement is sought through closing poorly performing schools, teacher salaries are based on performance measures, etc. The notion of unpredictability as a primary accompaniment of turbulence throws such efforts into relief by cautioning us that the consequences of qualitative transformation cannot always be fully overseen and therefore calls attention to the risk assumption associated with these approaches.

There are also larger questions in the field to which complexity perspectives can usefully contribute such as the relation between the individual and society at large (Biesta, 2010; Simmons \& Olssen, 2010) and the potential transmission of inequality through education (Guevara, Lopez, Posch, \& Zuniga, 2014; Guevara \& Porta, 2016). While the potential of complexity perspectives to address such questions is considerable, their success is predicated on a clear shared understanding of our terminology and the diversity of its expression, to which this article aimed to meaningfully contribute. CDS presents us with a clear alternative to traditional linear and reductionist approaches to scientific research, and the capacity of CDS to address the questions to which those approaches have failed to provide satisfying answers will be enhanced if there is clarity about the underlying constructs.

\section{Acknowledgement}

A preliminary version of this paper was presented at the annual meeting of the Society for Chaos Theory in Psychology and Life Sciences, Salt Lake City, UT, July 30, 2016.

\section{References}

Abraham, F. D. (1995). A postscript on language, modeling and metaphor. In F. D. Abraham \& A. R. Gilgen (Eds.) Chaos Theory in Psychology (pp. 311-342). Westport, CT: Praeger.

Alhadeff-Jones, M. (2008). Three generations of complexity theories: Nuances and ambiguities. Educational Philosophy and Theory, 40, 66-82. 
Alhadeff-Jones, M. (2010). The reduction of critique in education: Perspectives from Morin's paradigm of complexity. In Osberg, D. \& G. Biesta, G. (Eds.) Complexity theory and the politics of education (Pp. 25-37). Rotterdam, Netherlands: Sense Publishers.

Ashby, W. R. (1957). An introduction to cybernetics. London: Chapman \& Hall.

Ashby, W. R. (2004/1962). Principles of the self-organizing system. Emergence, Complexity and Organization, 6, 102-126. [Reprinted from H. von Foerster and G. W. Zopf (Eds.) Principles of self-organization: Transactions of the University of Illinois Symposium. London: Pergamon Press (pp. 255-278). ]

Bai, H., \& Banack, H. (2006). 'To see the world in a grain of sand': Complexity ethics and moral education. Complicity: An International Journal of Complexity and Education, 3, 5-20.

Bak, P. (1996). How nature works: The science of self-organized criticality. New York: Springer.

Biesta, G. (2010). Five theses on complexity reduction and its politics. In D. Osberg, \& G. Biesta (Eds.) Complexity theory and the politics of education (pp. 5-13). Rotterdam, Netherlands: Sense Publishers.

Bogdan, R. C., \& Biklen, S. K. (1982). Qualitative research for education: An introduction to theory and methods. Boston: Allyn \& Bacon.

Coglan, D., \& Brannick, T. (2014). Doing action research in your own organization. $4^{\text {th }}$ Edition. Thousand Oaks, CA: Sage.

Davis, B., \& Sumara, D. (2006). Complexity and education: Inquiries into learning, teaching and research. New York: Routledge.

Doll, Jr. W. (2008). Complexity and the culture of curriculum. Educational Philosophy \& Theory, 40, 190-212.

Finerty, S. Z. (2012). Master the matrix: Seven essentials for getting things done in complex organizations. Minneapolis: Two Harbors Press.

Fleener, M. J., \& Merritt, M. L. (2007). Paradigms lost? Nonlinear Dynamics in Psychology and Life Sciences, 11, 118.

Fromberg, D. P. (2010). How nonlinear systems inform meaning and early education. Nonlinear Dynamics, Psychology and Life Sciences, 14, 47-68.

Fromberg, D. P. (2016). The fractal dynamics of early childhood play, development, and nonlinear teaching and learning. In M. Koopmans, \& D. Stamovlasis (Eds.) Complex dynamical systems in education: Concepts, methods and applications (pp. 105-118). New York: Springer.

Garner, J. K., \& Russell, D. M. (2016). The symbolic dynamics of visual attention during learning: Exploring the application of orbital decomposition. In M. Koopmans, \& D. Stamovlasis (Eds.) Complex dynamical systems in education: Concepts, methods and applications (pp. 345-377). New York: Springer.

Gilstrap, D. L. (2011). Human ecological complexity: Epistemological implications of social networking an emerging curriculum theories. Complicity: An International Journal of Complexity and Education, 2, 36-51.

Ginsburg, H. P., \& Opper, S. (1988). Piaget's theory of intellectual development ( $3^{\text {rd }}$ Edition). Englewood Cliffs, NJ: Prentice Hall.

Goldspink, C. (2007). Rethinking educational reform: A loosely coupled and complex systems perspective. Educational Management, Administration \& Leadership, 35, 27-50.

Goldstein, J. (1988). A far-from-equilibrium systems approach to resistance to change. Organizational Dynamics, $17,16-26$.

Goldstein, J. (1990). A non-equilibrium nonlinear approach to nonlinear change. In D. Anderson, G. Richardson, \& J. Sterman (Eds.) System dynamics '90 (pp. 425-439). Cambridge, MA: MIT Press.

Goldstein, J. (1995). The Tower of Babel in nonlinear dynamics: Toward the clarification of terms. In R. Robertson \& A. Combs (Eds.) Chaos theory in psychology and the life sciences. Mahwah, NJ: Erlbaum. (Pp. 3947)

Goldstein, J. (1999). Emergence as a construct: History and issues. Emergence, 1, 49-72.

Goldstein, J. (2014). Reimagining emergence, Part 3: Uncomputability, transformation, and self-transcending constructions. Emergence: Complexity and Organization, 16, 116-176.

Guastello, S. J. \& Gregson, R. A. M. (2011). Nonlinear dynamical systems analysis for the behavioral sciences using real data. Boca Raton, FL: CRC Press/Taylor \& Francis. 
Guevara, P., Lopez, L., Posch, A, \& Zuniga, R. (2014). A dynamic nonlinear model for educational systems: A simulation of study for primary education. Nonlinear Dynamics, Psychology and Life Sciences, 18, 91-108.

Guevara, P., \& Porta, E. (2016). Educational systems and the intergenerational transmission of inequality: A complex dynamical systems perspective. In M. Koopmans, \& D. Stamovlasis (Eds.) Complex dynamical systems in education: Concepts, methods and applications (pp. 323-343). New York: Springer.

Haken, H. (1984). The science of structure: Synergetics. New York: Van Nostrand Reinhold.

Haken, H. (1988). Information and self-organization: A macroscopic approach to self-organization. New York: Springer.

Hess, F. M. (1999). Spinning wheels: The politics of urban school reform. Washington, DC: Brookings Institution.

Hetherington, L. (2013). Complexity thinking and methodology: The potential of 'complex case study' for educational research. Complicity: An International Journal of Complexity and Education, 10, 71-85.

Holland, J.H. (2002) Complex adaptive systems and spontaneous emergence. In A.Q. Curzio, \& M. Fortis (Eds), Complexity and Industrial Clusters. Germany. Physica-Verlag, Heidelberg, pp. 24-34.

Hussain, H., Conner, L., \& Mayo, E. (2014). Envisioning curriculum as six simultaneities. Complicity: An International Journal of Complexity and Education, 11, 59-84.

Jensen, H. J. (1998). Self-organized criticality: Emergent complex behavior in physical and biological systems. Cambridge: Cambridge University Press.

Jörg, T. (2011). New thinking in complexity for the social sciences and humanities: A generative, transdisciplinary approach. New York: Springer.

Jörg, T., Davis, B., \& Nickmans, G. (2007). Position paper: Toward a new complexity science of learning and education. Educational Research Review, 2, 145-156.

Kauffman, S. A. (1993). The origins of order: Self-organization and selection in evolution. New York: Oxford University Press.

Koopmans, M. (2009). Epilogue: Psychology at the edge of chaos. In S. J. Guastello, M. Koopmans, \& D. Pincus (Eds.) Chaos and complexity in psychology: The theory of nonlinear dynamical systems (pp. 506-526). New York: NY: Cambridge University Press.

Koopmans, M. (2014). Change, self-organization and the search for causality in educational research and practice. Complicity: An International Journal of Complexity and Education, 11, 20-39.

Koopmans, M. (2015). When time makes a difference: Addressing ergodicity and complexity in education. Complicity: An International Journal of Complexity and Education, 12, 5-25.

Koopmans, M. (2016). Addressing the policy churn in public education in the United States. Nonlinear Dynamics, Psychology and Life Sciences, 20(3), 401-422.

Koopmans, M., \& Stamovlasis, D. (2016). Complex dynamical systems in education: Concepts, methods and applications. New York: Springer.

Kuhn, T. S. (1970). The structure of scientific revolutions (2nd Edition). Chicago: University of Chicago Press.

Laidlaw, L., Makovichuk, L, \& Wong, S. (2013, April). Complexity, pedagogy, play: On using technology within emergent learning structures with young learners. Presented at the annual meeting of the American Educational Research Association. San Francisco, CA.

Larsson, J., \& Dahlin, B. (2012). Educating far from equilibrium: Chaos in philosophy and the quest for complexity in education. Complicity: An International Journal of Complexity and Education, 9, 1-14.

Le Moigne, J. L. (2013). The intelligence of complexity: Do ethical aims of research and intervention in education not lead us to a new discourse "On the study methods of our time"? Complicity: An International Journal of Complexity and Education, 10, 1-17.

Lemke, J. \& Sabelli, N. H. (2008). Complex systems and educational change: Toward a new research agenda. Educational Philosophy and Theory, 40, 118-129.

Levinthal, D. A. (1997). Adaptation on rugged landscapes. Management Science, 43, 934 - 950.

Lewin, K. (1947). Frontiers in group dynamics: I. Concept, method and reality in social science, social equilibria, and social change. Human Relations, 1, 2-38.

Lewin, K. (1951). Field theory in social science. New York: Harper \& Row.

Lincoln, Y. S. \& Guba, E. G. (1985). Naturalistic inquiry. Newbury Park, CA: Sage. 
Low, K. (2008). Holy ground of teaching and learning. Complicity: An International Journal of Complexity and Education, 5, 149-154.

Maturana, H. R. (1970). Biology of cognition. In H. R. Maturana, \& F. J. Varela, F. J. (1980). Autopoiesis and Cognition: The realization of the living (pp. 1-58). Dordrecht: Reidel Publishing Company.

Maturana, H. R., \& Varela, F. J. (1973). Autopoiesis: The organization of the living. In H. R. Maturana, \& F. J. Varela, F. J. (1980). Autopoiesis and Cognition: The realization of the living (pp. 73-134). Dordrecht: Reidel Publishing Company.

McKelvey, B. (1999). Avoiding complexity catastrophe in coevolutionary pockets: Strategies for rugged landscapes. Organization Science, 10, 294-321.

McKelvey, B. (2011). A scientific realist epistemology for complexity science. In P. Allen, S. Maguire, \& B. McKelvey (Eds.) The Sage handbook of complexity and management (pp. 112-131). Thousand Oaks, CA: Sage.

Merriam-Webster, Inc. (1990). Webster's ninth new collegiate dictionary. Springfield, MA: Merriam-Webster Publishers.

Morin, E. (2008). On complexity. Cresskill, NJ: Hampton Press.

Nelson, C. (2004). The building blocks of learning. Complicity: An International Journal of Complexity and Education, 1, 35-59.

Nicolis, G., \& Prigogine, I. (1989). Exploring complexity: An introduction. New York: Freeman.

Osberg, D. \& Biesta, G. (2010) Complexity theory and the politics of education. Rotterdam, Netherlands: Sense Publishers.

Pennings, H. J. M. , \& Mainhard, T. (2016). Analyzing teacher-student interactions with state space grids. In M. Koopmans, \& D. Stamovlasis (Eds.) Complex dynamical systems in education: Concepts, methods and applications (pp. 233-271). New York: Springer.

Perrow, C. (2014). Complex organizations: A critical essay (4th Edition). Brattleboro, VT: Echo Point Books \& Media.

Piaget, J. (1967). Six psychological studies. New York: Vintage.

Piaget, J. (1970). Science of education and the psychology of the child. New York: Viking.

Piaget, J. (1971). Biology and knowledge: An essay on the relations between organic regulations and cognitive processes. Chicago: University of Chicago Press.

Phelps, R. (2005). The potential of reflective journals in studying complexity 'in action'. Complicity: An International Journal of Complexity and Education, 2, 37-54.

Prigogine, I. \& Stengers, I. (1984). Order out of chaos: Man's new dialogue with nature. New York: Bantam.

Rosen, R. (1985). Organisms as causal systems which are not mechanisms: An essay into the nature of complexity. In R. Rosen (Ed.) Theoretical biology and complexity: Three essays on the natural philosophy of complex systems (pp. 165-203). Orlando, FL: Academic Press.

Salem, P. (2013). The complexity of organizational change: describing communication during organizational turbulence. Nonlinear Dynamics, Psychology, and Life Sciences, 17, 49-65.

Semetsky, I. (2005). Not by breadth alone: Imagining a self-organised classroom. Complicity: An International Journal of Complexity and Education, 2, 19-36.

Shannon, C. E. (1948). A mathematical theory of communication. Bell System Technical Journal, 27, 279-423.

Simmons, M. \& Olssen, M. (2010). The school and learning apparatus. In D. Osberg, \& G. Biesta (Eds.). Complexity theory and the politics of education (pp. 79-91). Rotterdam: Sense Publishers.

Smitherman, S. (2005). Chaos and complexity theories: Wholes and holes in curriculum. In W. E. Doll, M. J. Fleener, D. Trueit, \& St. Julien, J. (Eds.) Chaos, complexity, curriculum, and culture: A conversation (pp. 153180). New York: Peter Lang.

Stamovlasis, D. (2006). The nonlinear dynamical hypothesis in science education problem solving: A catastrophe theory approach. Nonlinear Dynamics, Psychology and Life Sciences, 10, 37-70.

Stamovlasis, D. (2014). Bifurcation and hysteresis effects in student performance: The signature of complexity and chaos in educational research. Complicity: An International Journal of Complexity and Education, 11, 51 64. 
Stamovlasis, D., \& Tsaparlis, G. (2012). Applying catastrophe theory to an information processing model of problem solving in science education. Science Education, 96, 392-410.

Stamovlasis, D. (2016a). Catastrophe theory: Methodology, epistemology and applications in learning science. In M. Koopmans, \& D. Stamovlasis (Eds.) Complex dynamical systems in education: Concepts, methods and applications (pp. 141-175). New York: Springer.

Stamovlasis, D. (2016b). Nonlinear dynamical interaction patterns in collaborative groups: Discourse analysis with orbital decomposition. In M. Koopmans, \& D. Stamovlasis (Eds.) Complex dynamical systems in education: Concepts, methods and applications (pp. 273-297). New York: Springer.

St. Julien, J. (2005). Complexity: Developing a more useful analytic for education. In W. E. Doll, M. J. Fleener, D. Trueit, \& St. Julien, J. (Eds.) Chaos, complexity, curriculum, and culture: A conversation (pp. 101-116). New York: Peter Lang.

Stewart, I. (2007). Complicity and simplexity. Complicity: An International Journal of Complexity and Education, 4, 105-106.

Tijus, C., Poitrenaud, S., Zibetti, E., Jouen, F, Bui, M., Pinska, E. (2007, April). Complexity reduction: Theory, metrics and application. Conference paper for the IEEE International Conference on Research, Innovation and Vision for the Future. DOI: 10.1109/RIVF.2007.369137.

Trombly, C. E. (2014). Schools and complexity. Complicity: An International Journal of Complexity and Education, $11,40-58$.

Trueit, D. (2005). Watercourses: From poetic to poietic. In W. E. Doll, M. J. Fleener, D. Trueit, \& St. Julien, J. (Eds.) Chaos, complexity, curriculum, and culture: A conversation (pp. 77-99). New York: Peter Lang.

Urry, J. (2003). Global complexity. Cambridge: Blackwell.

van Geert, P., \& Steenbeek, H. (2014). The good, the bad and the ugly? The dynamic interplay between educational practice, policy and research. Complicity: An International Journal of Complexity and Education, 11, 22-39.

von Berthalanffy, L. S. (1967). Robots, men and minds: Psychology in the modern world. New York: Braziller. von Berthalanffy, L. S. (1969). General system theory. New York: George Braziller.

Waldrop, M. M. (1992). Complexity: The emerging science at the edge of order and chaos. New York: Touchstone. Wiener, N. (1961). Cybernetics, or control and communication in the animal and the machine (2nd Edition). Cambridge, MA: MIT Press.

\section{About the Author}

Matthijs Koopmans is an Associate Professor at Mercy College. His current research interests include the application of complex dynamical systems approaches to education, cause and effect relationships and nonlinear time series. Correspondence: mkoopmans@mercy.edu.

(C) Copyright 2017. The author, MATTHIJS KOOPMANS, assigns to the University of Alberta and other educational and non-profit institutions a non-exclusive license to use this document for personal use and in courses of instruction provided that the article is used in full and this copyright statement is reproduced. The authors also grant a non-exclusive license to the University of Alberta to publish this document in full on the World Wide Web, and for the document to be published on mirrors on the World Wide Web. Any other usage is prohibited without the express permission of the authors. 